\title{
A Review of Epidemiological Distribution of Different Types of Fractures in Paediatric Age \\ MN Baig $^{1}$
}

1. Orthopaedics, University Hospital Galway, Galway, IRL

$\square$ Corresponding author: MN Baig, nouman142@gmail.com

Disclosures can be found in Additional Information at the end of the article

\section{Abstract \\ Introduction}

Treating paediatric patient fractures comprises a large part of any orthopaedic trauma service. The majority of fractures take place during sports and recreational activities. In this study, we examined the incidence of fractures and their distribution according to patient age.

\section{Methods}

We collected retrospective data from all the paediatric age group patients (under age 18) referred to our orthopaedic service from August 2015 to July 2016. We collected data for 1022 patients during one calendar year.

\section{Results}

We noted 1022 paediatric fracture presentations in one calendar year, with a $48.63 \%$ incidence in male patients and $51.36 \%$ in female patients. The age with the highest incidence was 16 years in boys and 11 years in girls. Upper limb fractures were more common than lower limb fractures in most of the subgroups.

\section{Conclusions}

These insights into paediatric fracture distribution provide an opportunity to evaluate the resources in hospitals allocated to emergency and orthopaedic departments regarding their capacity to treat fractures in paediatric patients.

Received 07/11/2017

Review began 08/17/2017

Review ended 08/21/2017

Published 08/28/2017

C Copyright 2017

Baig. This is an open access article distributed under the terms of the Creative Commons Attribution License CC-BY 3.0., which permits unrestricted use, distribution, and reproduction in any medium, provided the original author and source are credited.
Categories: Pediatrics, Orthopedics, Public Health

Keywords: paediatrics, buckle fracture, supracondylar fracture

\section{Introduction}

Paediatric injuries comprise a large subset of emergency and orthopaedic outpatient presentations. The high number of paediatric injuries and fractures can be attributed to the enthusiasm typically seen in paediatric patients as they discover and experience new things while remaining unaware of the consequences. Bone properties of patients in this age group will also influence the incidence and pattern of fracture. Paediatric fractures constitute approximately $25 \%$ of all paediatric age group injuries [1]. The majority of fractures in paediatric patients are not life-threatening and are treatable [2]. Although there are many 
systemic and metabolic diseases that can cause or contribute to the fractures, the majority of these fractures are secondary to trauma [3].The aim of our study is to look at the incidence of fractures in paediatric patients, the prevalence of the different types of fractures, their gender distribution, and their relationship to certain activities or sports.

\section{Materials And Methods}

Our study is based on a retrospective collection of data of paediatric patients who presented with fractures to the orthopaedic outpatient services of University Hospital Kerry, as well as patients admitted for inpatient treatment. Patients under 18 years of age who presented to the University Hospital Kerry from August 2015 to July 2016 with fractures were included in the study. The epidemiological data was collected from the hospital and departmental medical records. All X-rays were reviewed to ensure that non-fracture or soft-tissue injuries were excluded. The data was collected on Microsoft Excel sheets and analysed using the Statistical Package for the Social Sciences (SPSS version 19.0, IBM, New York, USA).

\section{Results}

The total population of County Kerry (located in Southwest Ireland) is 147,554. The paediatric population (those under 18 years of age) is 34,940 , comprising $24.013 \%$ of the total population. A total of 1022 paediatric patients presented with fractures to the orthopaedic outpatient department, making the incidence rate 29.23 fractures/1000/year. The detailed results of the epidemiological distribution of fractures are shown in Table 1. 


\section{Cureus}

\begin{tabular}{|c|c|c|c|c|}
\hline Fracture & Frequency & Percent & Age (year) & Sex (Male:Female) \\
\hline Clavicle & 53 & 5.2 & 9.21 & $74: 26$ \\
\hline Proximal humerus & 18 & 1.8 & 11.56 & 44:56 \\
\hline Distal humerus/Supracondylar & 142 & 13.9 & 6.89 & $51: 49$ \\
\hline Radius/Ulna diaphysis & 36 & 3.5 & 9.42 & 50:50 \\
\hline Radius metaphysis & 58 & 5.7 & 8.41 & 41:59 \\
\hline Distal radius /Buckle & 278 & 27.2 & 8.48 & $54: 46$ \\
\hline Scaphoids & 35 & 3.4 & 13.37 & $40: 60$ \\
\hline Metacarpals & 51 & 5.0 & 14.02 & 47:53 \\
\hline Phalanx fingers & 85 & 8.3 & 12.85 & 39:61 \\
\hline Tibia diaphysis & 13 & 1.3 & 8.00 & 46:54 \\
\hline Distal tibia & 9 & 0.9 & 5.00 & 67:33 \\
\hline Femur diaphysis & 19 & 1.9 & 14.42 & 42:58 \\
\hline Proximal tibia & 25 & 2.4 & 8.56 & 88:12 \\
\hline Patella & 7 & 0.7 & 13.29 & 29:71 \\
\hline Ankle & 94 & 9.2 & 12.36 & $40: 60$ \\
\hline Toe phalanx & 16 & 1.6 & 12.88 & 44:56 \\
\hline Metatarsals & 26 & 2.5 & 11.23 & $54: 46$ \\
\hline Pubic rami & 3 & 0.3 & 16.00 & $0: 100$ \\
\hline Olecranon & 11 & 1.1 & 7.27 & 18:82 \\
\hline Hook of hamate & 7 & 0.7 & 14.00 & $57: 43$ \\
\hline Ulnar styloid & 18 & 1.8 & 12.00 & 100:0 \\
\hline Radial head & 18 & 1.8 & 8.33 & 33:67 \\
\hline
\end{tabular}

TABLE 1: Common fractures and their epidemiological distribution according to age, sex, and frequency of different types of fractures

The most common fracture was distal radial/buckle fractures (27.2\%), followed by distal humerus /supracondylar fracture (13.9\%), ankle fractures (9.2\%), phalanx fractures (8.3\%), and radial/ulnar metaphysis fractures (5.7\%). Figure 1 presents the nine most common fractures and their ratios. 


\section{Cureus}

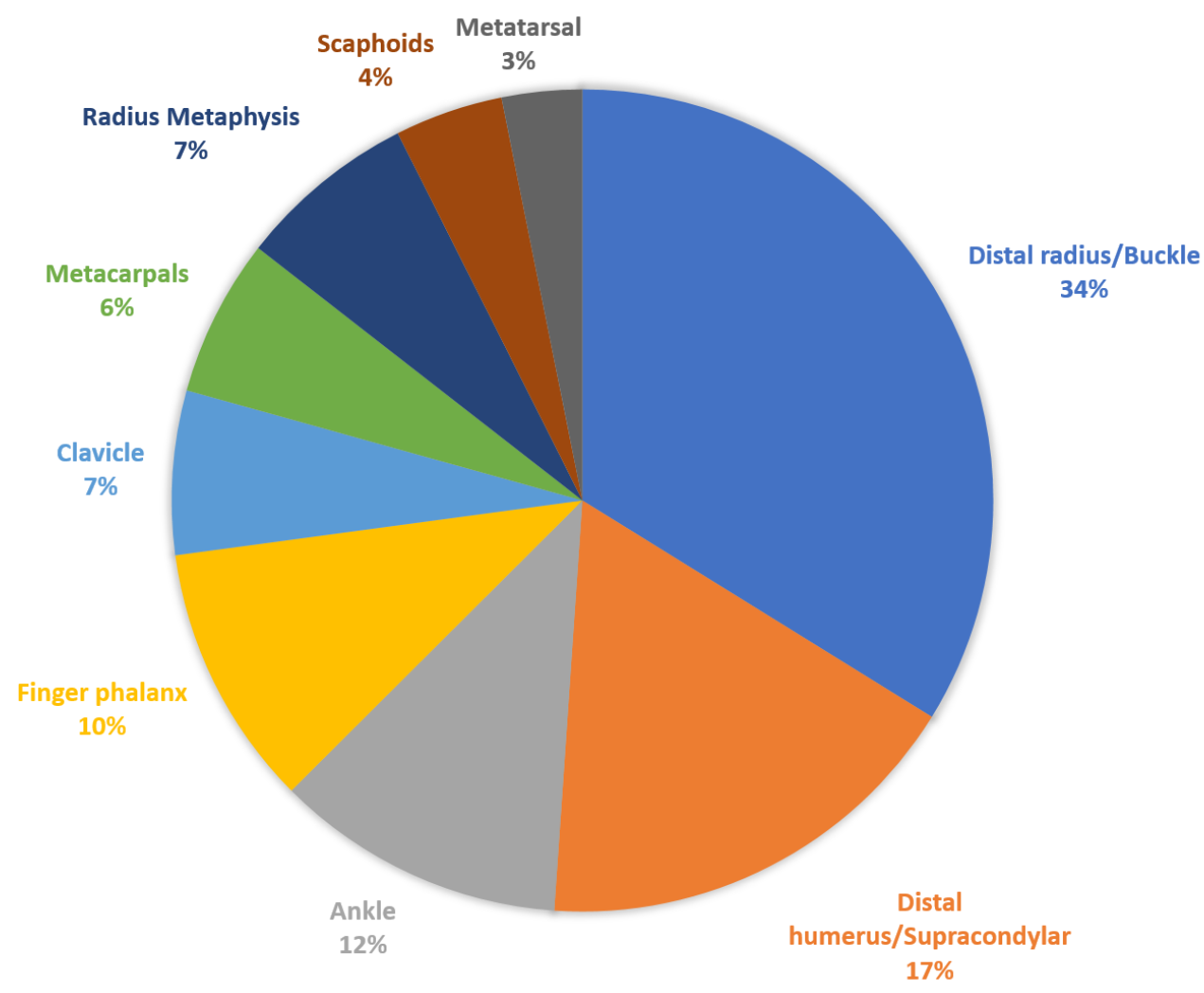

FIGURE 1: The nine most common fractures and their ratios

The mean age of paediatric patients presenting with distal radial fracture was 8.48 years with a male/female (M/F) ratio of 54:46. The mean age of paediatric patients presenting with distal humerus fracture was 6.89 years with an $\mathrm{M} / \mathrm{F}$ ratio of $51: 49$. The mean age of patients with ankle fractures was 12.36 years with an $\mathrm{M} / \mathrm{F}$ ratio of $40: 60$. The mean age of patients with a phalanx fracture was 12.85 years with an M/F ratio of 39:61. Finally, the mean age of patients with a radial/ulnar metaphysis fracture was 8.41 years with an M/F ratio of 41:59. Table 2 presents fracture data according to age, $\mathrm{M} / \mathrm{F}$ ratio, limb distribution, and common fractures. 


\section{Cureus}

\begin{tabular}{|c|c|c|c|c|}
\hline \multirow[t]{2}{*}{ Age group (years) } & \multirow{2}{*}{ Male (\%):Female (\%) } & Upper:Lower Limb (\%) & \multicolumn{2}{|c|}{ Five Most Common Fractures (\%) } \\
\hline & & & Distal radius / buckle fracture & 29.17 \\
\hline \multirow{3}{*}{$0-2$} & \multirow{3}{*}{ 33:67 } & \multirow{3}{*}{ 100:0 } & Distal humerus/supracondylar & 25 \\
\hline & & & Clavicle & 25 \\
\hline & & & Ankle & 12.5 \\
\hline \multirow{5}{*}{$3-6$} & \multirow{5}{*}{ 50:50 } & \multirow{5}{*}{$81: 19$} & Distal humerus/supracondylar & 32.35 \\
\hline & & & Distal radius /buckle fracture & 32.35 \\
\hline & & & Radius metaphysis & 9.66 \\
\hline & & & Clavicle & 7.56 \\
\hline & & & Proximal tibia & 6.3 \\
\hline \multirow{5}{*}{ 7-12 } & \multirow{5}{*}{ 45:55 } & \multirow{5}{*}{$74: 26$} & Distal radius/buckle fracture & 37.28 \\
\hline & & & Distal humerus/supracondylar & 11.61 \\
\hline & & & Ankle & 8.93 \\
\hline & & & Phalanx fingers & 8.705 \\
\hline & & & Radius/ulna diaphysis & 8.036 \\
\hline \multirow{5}{*}{ 13-17 } & \multirow{5}{*}{$54: 46$} & \multirow{5}{*}{ 66:34 } & Ankle & 14.74 \\
\hline & & & Phalanx fingers & 14.74 \\
\hline & & & Metacarpals & 13.78 \\
\hline & & & Distal radius /buckle fracture & 8.65 \\
\hline & & & Scaphoids & 8.33 \\
\hline
\end{tabular}

TABLE 2: Paediatric subgroups according to age with sex ratio, limb distribution, and common fracture distribution

Up to the age of two years, the most common fractures were distal radial buckle fractures (29.17\%), followed by distal humerus/supracondylar fractures in $25 \%$ of patients in this age group. Between the ages of three and six years, the most common fractures presented were distal humerus/supracondylar fractures (32.35\%), distal radial/buckle fractures (32.35\%), and radial/ulnar metaphysis fractures (9.66\%). Between age seven and age 12 , the most common fractures were distal radial/buckle fractures (37.28\%), followed by supracondylar fractures (11.61\%) and ankle fractures (8.93\%). In patients aged 13 to 17 , the most common fractures were ankle fractures (14.74\%), phalanx fractures (14.74\%), followed by metacarpal fractures (13.78\%). Table 3 presents the fracture epidemiology according to activities. 


\section{Cureus}

Activity or

Mechanism

Men

Blunt trauma

9.889

5.737

Fall from bed/chair

Fall on outstretched hand

7.864

14

Gaelic Soccer

13.034

Hockey

Hurling

(years)

11.417
Mean Age

40:60

$22: 78$

Male (\%): Female

(\%)

(\%)

er: Lower Limb

(

49:51

66:34

$76: 24$

80:20
$54: 46$

83:17

$74: 26$

98:2

$84: 16$

$90: 10$

Metacarpals

25

Phalanx fingers

Toe phalanx

Clavicle

Proximal humerus

Phalanx fingers

16.6

Metatarsals

16.6

Clavicle

Distal hum/supracondylar

20

Proximal tibia

Distal radius/buckle

fracture

Scaphoids

Distal radius/buckle fracture

Radius metaphysis

Scaphoids

7.24

Distal radius/buckle

fracture

Clavicle

Phalanx fingers

Radius metaphysis

Phalanx fingers

Metacarpals

27.5

Olecranon

10.3

Ankle

Phalanx fingers

Distal radius/buckle fracture

$93: 7$
Proximal humerus $\quad 20$

Metacarpals 10 


\section{Cureus}

\begin{tabular}{|c|c|c|c|c|c|}
\hline & & & & Scaphoids & 10 \\
\hline \multirow{3}{*}{ Camogie } & \multirow{3}{*}{12.667} & \multirow{3}{*}{ 100:0 } & \multirow{3}{*}{$67: 33$} & Phalanx fingers & 33.3 \\
\hline & & & & Ankle & 33.3 \\
\hline & & & & Radius/ulna diaphysis & 33.3 \\
\hline \multirow{2}{*}{ Rugby } & \multirow{2}{*}{14} & \multirow{2}{*}{$0: 100$} & \multirow{2}{*}{ 100:0 } & Clavicle & 66.6 \\
\hline & & & & Phalanx fingers & 33.3 \\
\hline \multirow{3}{*}{ Soccer } & \multirow{3}{*}{10.937} & \multirow{3}{*}{ 45:55 } & \multirow{3}{*}{ 69:31 } & $\begin{array}{l}\text { Distal radius/buckle } \\
\text { fracture }\end{array}$ & 35.4 \\
\hline & & & & Ankle & 21.7 \\
\hline & & & & Radius/ulna metaphysis & 10.2 \\
\hline \multirow{3}{*}{$\begin{array}{l}\text { Trampoline/monkey } \\
\text { bar }\end{array}$} & \multirow{3}{*}{7.256} & \multirow{3}{*}{$46: 54$} & \multirow{3}{*}{ 95:5 } & $\begin{array}{l}\text { Distal } \\
\text { humerus/supracondylar }\end{array}$ & 80.8 \\
\hline & & & & $\begin{array}{l}\text { Distal radius/buckle } \\
\text { fracture }\end{array}$ & 9.6 \\
\hline & & & & Ankle & 4.8 \\
\hline
\end{tabular}

\section{TABLE 3: Common fractures caused during different sports/activities}

A commonly reported cause of injury was blunt trauma, occurring in 54\% of the fractures of the upper limb and $46 \%$ of the fractures of the lower limb. The most common fractures due to blunt trauma were metacarpal fractures (25\%), finger phalanx and foot phalanx fractures (12\% each), followed by ankle fractures (11.11\%). Another common mechanism was falling on an outstretched hand, and the associated fractures were distal radial fractures (72.4\%), radial metaphysis fractures (9.5\%), scaphoid fractures (7.24\%), and radial head fractures (2.71\%). Fractures associated with trampolines, monkey bars, and bouncing castles were common in younger children. The most common fracture pattern seen in these activities was distal humerus/supracondylar fractures (80.8\%), distal radial/buckle fractures (9.6\%), followed by ankle and phalanx fractures (4.8\% each). The fracture pattern seen resulting from Gaelic football injuries were distal radial/buckle fractures (17.28\%), clavicle fractures (13.58\%), finger phalanx fractures (13.58\%), radial/ulnar fractures (12.35\%), and distal humerus/supracondylar, metacarpals, and tibia fractures (7.41\% each). Fractures associated with hurling (a popular outdoor stick and ball field sport) were finger phalanx, distal radius, and proximal humerus fractures (20\% each), followed by metacarpal and scaphoid fractures (10\% each).

In the female population, camogie (a sport similar to hurling) and hockey are very popular activities. The most common fracture seen in camogie players were the ankle, phalanx, and radial/ulnar shaft fractures (33.3\% each). For hockey players, finger phalanx fractures were most common (34.48\%), followed by metacarpal fractures (27.59\%), ankle (10.34\%), and olecranon fractures (10.34\%). Fractures associated with soccer were distal radial/buckle fractures (35.43\%), ankle fractures (21.7\%), and radial/ulnar metaphysis fractures $(10.29 \%)$.

The other common activities/mechanisms reported included cycling, road and traffic accidents 


\section{Cureus}

(RTA), and falls from beds or chairs. See Table 3 for common fractures during those activities. The distribution of fractures in male/female population and the fracture distribution according to age is shown in Figure 2.
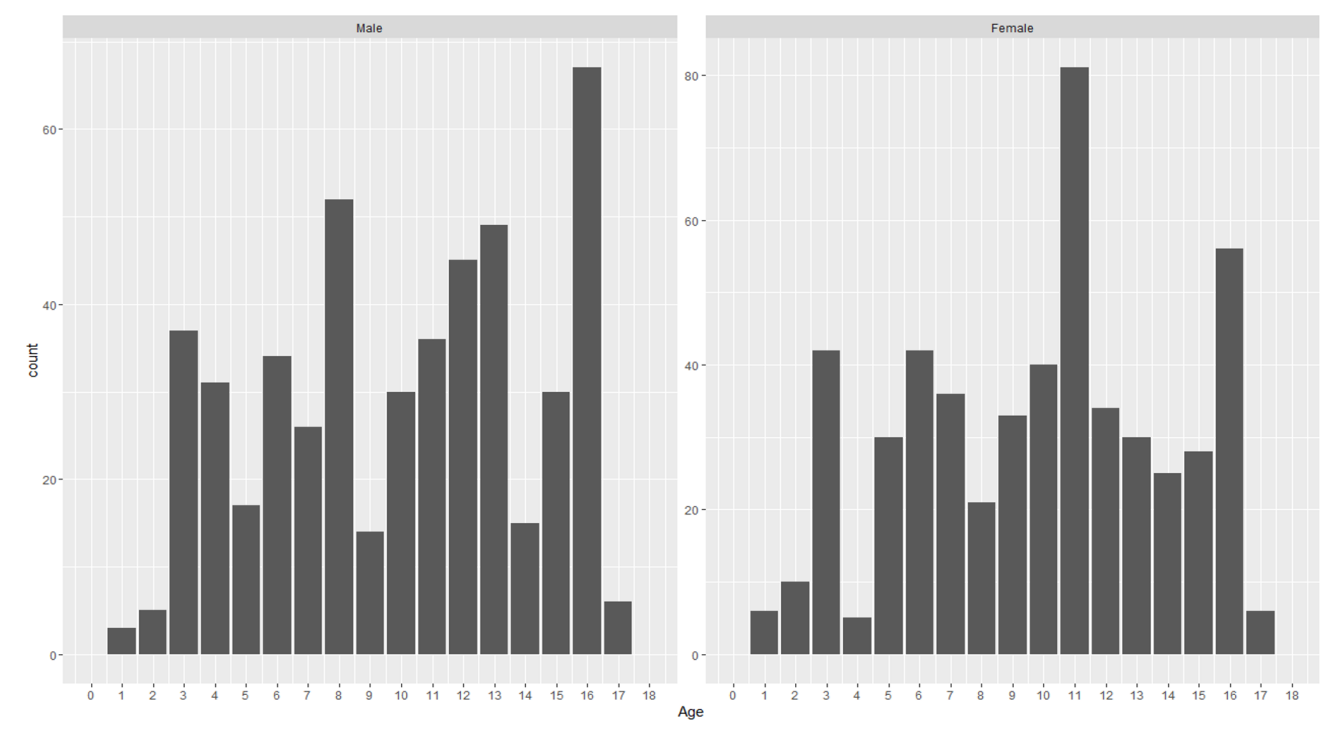

\section{FIGURE 2: Distribution of fractures in the male/female population and fracture distribution according to age}

\section{Discussion}

Fractures commonly occur in paediatric and elderly patients because of relatively weaker points of physis and metaphysis, and in elderly patients because of deteriorated bone quality [4]. The incidence rate of fractures in the paediatric population has ranged from 12.8/1000 as reported by Kopjar, et al. in Norway [2] to 36.1/1000 as described by Lyons, et al. [5] in Wales. The incidence rate in our study was 29.2/1000, near the higher end of the range. Many variables can affect the incidence, including the size of the paediatric population and the social emphasis on encouraging physical activity. The distribution of fractures between the upper and lower limbs has a certain pattern depending on the age. Early in life, children's activities utilise upper limbs rather than lower limbs, but as they start walking and running, the incidence of lower limb fractures increases.

According to our findings, the distribution of upper and lower limb fractures show specific trends that are quite representative of the nature of the sports related to those fractures. The distribution of fractures among male and females is shifted more towards males in our study, which may be due to the difference in activity levels. In the literature, distal radial fractures are the most common fractures in all paediatric age groups, which aligns with our findings [6]. The incidence and pattern of the fractures differ by location due to lifestyle differences such as rural vs. urban, area topography, and social and economic parameters.

\section{Conclusions}

This study provides an accurate assessment of the fractures in paediatric patients distributed by type, age, gender, and activity. This information can help allocate resources for dealing with these injuries in emergency and outpatient departments. These findings may also help healthcare professionals educate parents, guardians, school staff, paramedic staff, hospital staff, and the public in general, on common injuries in children and their relations to certain 
activities, in efforts to help minimise those injuries.

\section{Additional Information \\ Disclosures}

Human subjects: Consent was obtained by all participants in this study. Animal subjects: All authors have confirmed that this study did not involve animal subjects or tissue. Conflicts of interest: In compliance with the ICMJE uniform disclosure form, all authors declare the following: Payment/services info: All authors have declared that no financial support was received from any organization for the submitted work. Financial relationships: All authors have declared that they have no financial relationships at present or within the previous three years with any organizations that might have an interest in the submitted work. Other relationships: All authors have declared that there are no other relationships or activities that could appear to have influenced the submitted work.

\section{References}

1. Rennie L, Court-Brown CM, Mok JYQ, et al.: The epidemiology of fractures in children . Injury. 2007, 38:913-22. 10.1016/j.injury.2007.01.036

2. Kopjar B, Wickizer T: Fractures among children: incidence and impact on daily activities . Inj Prev. 1998, 4:194-7. 10.1136/ip.4.3.194

3. Valerio G, Gallè F, Mancusi C, et al.: Pattern of fractures across pediatric age groups: analysis of individual and lifestyle factors. BMC Public Health. 2010, 10:656. 10.1186/1471-2458-10656

4. Hedström EM, Svensson O, Bergström U, et al.: Epidemiology of fractures in children and adolescents. Acta Orthop. 2010, 81:148-53. 10.3109/17453671003628780

5. Lyons R, Delahunty A, Kraus D, et al.: Children's fractures: a population based study . Inj Prev. 1999, 5:129-32. 10.1136/ip.5.2.129

6. Cooper C, Dennison EM, Leufkens HG, et al.: Epidemiology of childhood fractures in Britain: a study using the general practice research database. J Bone Miner Res. 2004, 1:1976-81. 10.1359/JBMR.040902 